\title{
Neurosurgical untethering with or without syrinx drainage results in high patient satisfaction and favorable clinical outcome in post- traumatic myelopathy patients
}

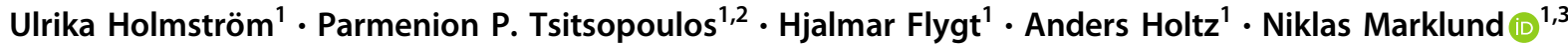

Received: 20 December 2017 / Revised: 2 March 2018 / Accepted: 6 March 2018 / Published online: 27 March 2018

(c) International Spinal Cord Society 2018

\begin{abstract}
Study design Retrospective data collection and patient-reported outcome measures.

Objectives To investigate surgical outcome, complications, and patient satisfaction in patients with chronic SCI and symptomatic post-traumatic progressive myelopathy (PPM) who underwent neurosurgical untethering and/or spinal cord cyst drainage with the aim of preventing further neurological deterioration.

Setting Single-center study at an academic neurosurgery department.

Methods All SCI patients who underwent neurosurgery between 1996 and 2013 were retrospectively included. All medical charts and the treating surgeon's operative reports were reviewed to identify surgical indications, surgical technique, and post-operative complications. A questionnaire and an EQ-5D-instrument were used to assess patient's self-described health status and satisfaction at long-term follow-up.

Results Fifty-two patients (43 men, 9 women) were identified, of whom five were dead and one was lost to follow-up. Main indications for surgery were pain $(54 \%)$, motor $(37 \%)$, or sensory $(8 \%)$ impairment, and spasticity $(2.0 \%)$. Overall complications were rare (8\%). At follow-up, the subjectively perceived outcome was improved in 24 and remained unchanged in 21 patients. Thus, the surgical aim was met in $87 \%$ of patients. Of the 46 eligible patients, 38 responded to the questionnaire of whom $65 \%$ were satisfied with the surgical results. Patients with cervical lesions were more satisfied with the surgical treatment than patients with thoracic/thoracolumbar lesions $(p=0.05)$.

Conclusions Neurosurgical untethering and/or cyst drainage in chronic SCI patients and PPM resulted in a high degree of patient satisfaction, particularly in cervical SCI patients with minimal complications.
\end{abstract}

\section{Introduction}

At time of spinal trauma, the spinal cord may be injured leading to various degrees of neurological dysfunction at and below the affected level $[1,2]$. A minor proportion of

Deseased: Anders Holtz.

Niklas Marklund

niklas.marklund@neuro.uu.se

1 Department of Neuroscience and Neurosurgery, Uppsala University, Uppsala, Sweden

2 Hippokratio General Hospital, Aristotle University, Thessaloniki, Greece

3 Department of Clinical Sciences Lund, Neurosurgery, Lund University, Skåne University Hospital, Lund, Sweden patients, most commonly those with incomplete SCI, show a degree of neurological improvement during the first period post injury [3]. However, most disabilities seen in SCI patients are chronic and do not recover significantly with time $[4,5]$.

After a period ranging from few months up to several decades following the initial injury, a subset of SCI patients may present with gradual worsening of the neurological deficits or may develop new symptoms resulting from progressive post-traumatic myelopathy (PPM). The clinical entity of PPM includes the classical symptoms of pain, disturbance of motor and sensory function, impairment of temperature sensation, hyperhidrosis, autonomic dysfunction, increased spasticity, Horner's syndrome, and impaired bladder and bowel control [4, 6-12].

The relationship between spinal arachnoid scarring and syringomyelia was recognized as early as 1938 [13]. Scar formation and spinal cord tethering are considered causative 
Fig. 1 Flow chart and patient material. SCI spinal cord injury, PPM post-traumatic progressive myelopathy, MVA motor vehicle accident, AIS American Spinal Injury Association Impairment Scale

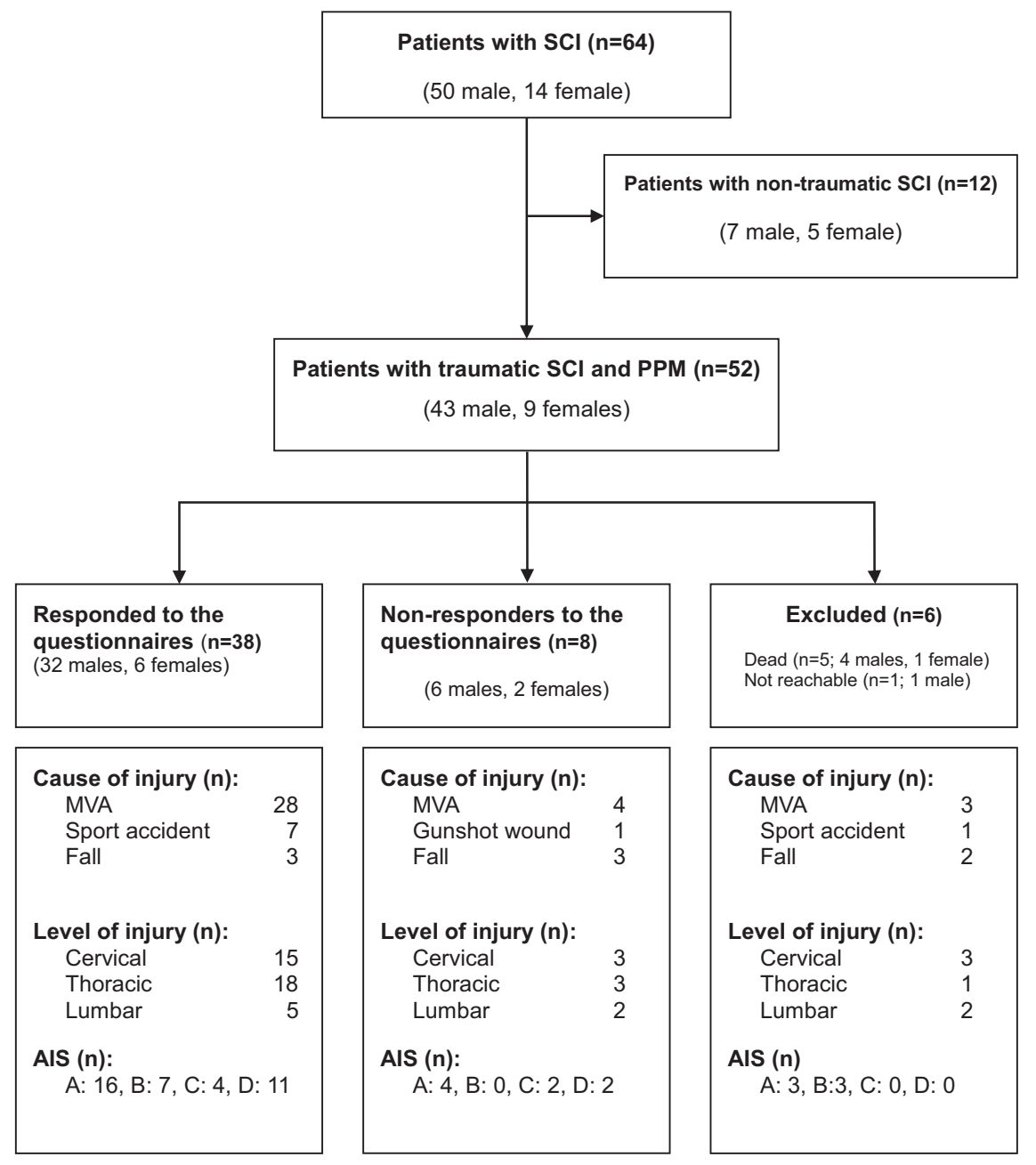

factors for cyst formation [4, 13-15]. This condition was initially named post-traumatic syringomyelia, a term still commonly used [7, 9, 10, 13 16-18]. However, since not all clinically evident exacerbations in chronic SCI patients are associated with spinal cord cyst formation, the term progressive PPM was coined. In PPM, neurological deterioration due to tethering may or may not be associated with syringomyelia [4, 8].

The pathophysiology of PPM has not been well explained. Since SCI patients commonly spend the initial post-injury phase in supine position due to inability for early mobilization, blood products may accumulate in the dorsal part of the cord, explaining the high incidence of dorsal tethering $[11,17]$. It is generally accepted that the development of syringomyelia results largely from the extent and degree of arachnoid adhesion and obstruction $[14,18,19]$. Of note, the proportion of SCI patients developing clinically significant PPM has been suggested to be $0.3-4.5 \%$ but according to magnetic resonance imaging
(MRI) or autopsy studies, the prevalence may be substantially higher, up to $30 \%[9,17,20,21]$.

Treatment of chronic SCI patients developing the clinical features of PPM is surgical with the primary aim to arrest further neurological deterioration [4, 12, 16]. Numerous surgical techniques have been described [4, 12, 20 22-24] with the most common being untethering of the cord with removal of the glial scar (arachnolysis), duraplasty and, when indicated, drainage of the associated cyst(s) [4, 14, 20]. Although the surgical strategy has previously been evaluated [4, 6, 14, 16, 20], complications and patient-related outcomes have been infrequently reported in the literature [4].

The current study was conducted with the aim to present the clinical picture, identify surgical indications and complication rates, as well as to analyze the long-term quality of life and patient satisfaction following neurosurgical treatment in patients with PPM. 

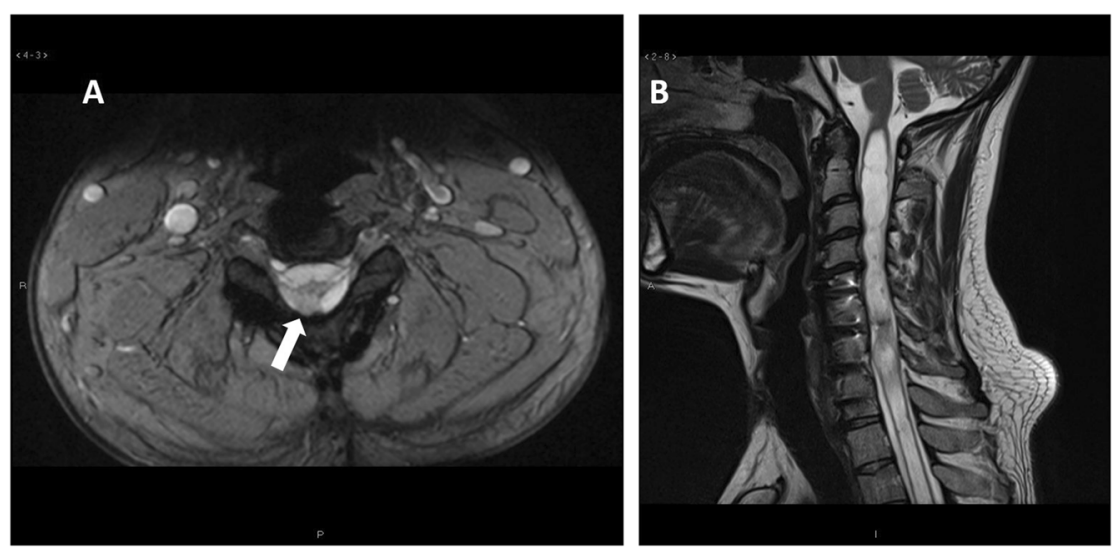

Fig. 2 a Axial T2-weighted magnetic resonance imaging (MRI) of the cervical spine showing typical appearance of a tethered spinal cord, resulting in the clinical picture of progressive post-traumatic myelopathy. Dorsally (arrow) there is evidence of the injured spinal cord adhering to the posterior part of the spinal cord to the dural sac. b A previous spinal cord injury patient presenting with ascending motor and sensory deficits. As shown on this sagittal T2-weighted MRI, there is a large syringomyelia extending to the rostral cervical spinal cord

\section{Methods}

The study was approved by the regional ethics committee of Uppsala, Sweden (decision number 2008/303). Since the study is retrospective, no informed patient consent was deemed necessary for the analysis of clinical, radiological, and surgical characteristics. However, each respondent who completed the questionnaire signed an informed consent form.

\section{Patients and setting}

The clinical cohort (Fig. 1) involved all traumatic SCI patients who had surgery for PPM including untethering/ arachnolysis and/or cyst drainage in the Department of Neurosurgery, at Uppsala University Hospital, Uppsala, Sweden between October 1996 and April 2013. The medical charts of each patient were retrospectively reviewed. The patients were identified by diagnosis and surgical codes as well as from the treating neurosurgeon's (AH) own operative reports. In all included patients, a gradual exacerbation of neurological symptoms was observed. The indication for surgery was predominately based on the clinical symptoms attributed to PPM, although supported by radiological findings showing signs of tethering with or without cyst formation. A preoperative MRI was performed in all patients, except for two patients in whom CT-myelography was performed due to contraindications for MRI. The MRI was retrospectively assessed for syrinx formation, deformities, adhesions, and/ or intramedullary signal abnormalities (Fig. 2a, b). Patients with SCI who underwent spinal column deformation correction surgery, intrathecal baclofen for spasticity or morphine pump implantation for pain were excluded. Other exclusion criteria were spinal cord tethering and/or syringomyelia due to non-traumatic causes such as congenital, post-infectious, and post-hemorrhagic tethering.

\section{Surgical technique}

All surgeries were performed with the patient in prone position fixed in a Mayfield head clamp (above Th8) or in Wilson frame (below Th8). Antibiotic prophylaxis was used pre-operatively, and limited decompression by laminectomy was performed centered at the level of interest indicated by the initial injury and pre-operative MRI findings. The dura was widely exposed.

Prior to dural opening, an ultrasound was applied for the visualization of the intradural content and the presence of intradural and/or intramedullary cysts [4]. Dural opening and all subsequent intradural procedures were carried out under the operating microscope. The flow of cerebrospinal fluid (CSF) and pulsation of the spinal cord was noted. Arachnoidal adhesions were sharply dissected using microneurosurgical techniques aiming for the release of CSF flow. Dissection was carried out laterally, although not anteriorly to the cord [4]. A repeat ultrasound evaluation was performed after the arachnoidal dissection was completed, to evaluate cyst appearance in order to decide whether syringo-subarachnoidal shunting should follow or not. A shunt was inserted only if the syrinx remained at $>50 \%$ of its original, pre-untethering, size. If the indications for shunting persisted, a shunt catheter was inserted into the syrinx as far rostrally as possible following a midline myelotomy. The dura was closed by suturing a dural patch (Neuro-Patch ${ }^{\circledast}$, B. Braun Medical Supplies, Melsungen, Germany, Inc. Neuropatch in the initial surgeries of this 
Table 1 Main indication for surgery, level of injury, and outcome assessed from the medical charts

\begin{tabular}{|c|c|c|c|c|c|c|}
\hline Op indication & Level of injury & Improved & Unchanged & Worse & No information & Total \\
\hline \multirow[t]{3}{*}{ Pain } & Cervical $(\mathrm{C} 0-\mathrm{C} 7)$ & $7(70 \%)$ & $3(30 \%)$ & $0(0 \%)$ & $0(0 \%)$ & $10(100 \%)$ \\
\hline & Thoracic (Th1-Th9) & $4(50 \%)$ & $4(50 \%)$ & $0(0 \%)$ & $0(0 \%)$ & $8(100 \%)$ \\
\hline & $\begin{array}{l}\text { Thoracolumbar } \\
\text { (Th10-L5) }\end{array}$ & $5(50 \%)$ & $4(40 \%)$ & $0(0 \%)$ & $1(10 \%)$ & $10(100 \%)$ \\
\hline \multirow[t]{3}{*}{ Motor function } & Cervical (C0-C7) & $3(33 \%)$ & $4(44 \%)$ & $2(22 \%)$ & $0(0 \%)$ & $9(100 \%)$ \\
\hline & Thoracic (Th1-Th9) & $2(29 \%)$ & $2(29 \%)$ & $2(29 \%)$ & $1(14 \%)$ & $7(100 \%)$ \\
\hline & $\begin{array}{l}\text { Thoracolumbar } \\
\text { (Th10-L5) }\end{array}$ & $1(33 \%)$ & $2(67 \%)$ & $0(0 \%)$ & $0(0 \%)$ & $3(100 \%)$ \\
\hline \multirow{3}{*}{$\begin{array}{l}\text { Sensory } \\
\text { function }\end{array}$} & Cervical (C0-C7) & $1(50 \%)$ & $1(50 \%)$ & $0(0 \%)$ & $0(0 \%)$ & $2(100 \%)$ \\
\hline & Thoracic (Th1-Th9) & $0(0 \%)$ & $1(50 \%)$ & $1(50 \%)$ & $0(0 \%)$ & $2(100 \%)$ \\
\hline & $\begin{array}{l}\text { Thoracolumbar } \\
\text { (Th10-L5) }\end{array}$ & - & - & - & - & - \\
\hline \multirow[t]{3}{*}{ Spasticity } & Cervical (C0-C7) & - & - & - & - & - \\
\hline & Thoracic (Th1-Th9) & $1(100 \%)$ & $0(0 \%)$ & $0(0 \%)$ & $0(0 \%)$ & $1(100 \%)$ \\
\hline & $\begin{array}{l}\text { Thoracolumbar } \\
\text { (Th10-L5) }\end{array}$ & - & - & - & - & - \\
\hline Total & & $24(46 \%)$ & $21(40 \%)$ & $5(10 \%)$ & $2(4 \%)$ & $52(100 \%)$ \\
\hline
\end{tabular}

patient series or Durepair ${ }^{\circledast}$, Medtronic, Memphis, TN, USA in the later cases) with additional tenting dural sutures when deemed necessary. Following dural closure using running sutures, tissue glue (Tisseel ${ }^{\circledR}$, Baxter International, Westlake Village, CA, USA) was applied. The wound was closed in layers including continuous non-resorbable skin sutures. Prophylactic lumbar drainage was used in seven patients. Neurophysiological monitoring using sensory and motor evoked potentials were used intraoperatively in 10 patients with incomplete SCI.

\section{Outcome measures}

All complications and reoperations were identified from the medical charts. At 3 months after surgery, outcome was recorded from the medical charts and defined as improved, unchanged or deteriorated, based on the perceived outcome reported by the patients to the treating surgeon (Table 1). Since the aim of surgery was to prevent and arrest further neurological deterioration, the definition for reaching the surgical goals was subjective improvement of pre-operative symptoms or unchanged post-operative status. At the time of long-term follow-up, an EQ-5D instrument was sent to each patient. The aim of using the EQ-5D instrument was to test the hypothesis that there was a difference in health status related to (a) patient satisfaction with the surgical outcome, (b) AIS level, i.e., motor complete (AIS A + B) or incomplete (AIS C + D) SCI, (c) gender, and (d) level of SCI. The EQ-5D instrument is a standardized measure of health status developed by the EuroQol Group in order to provide a simple, generic measure of health for clinical and economic appraisal [25]. The dimensions of EQ-5D are mobility, self-care, usual activities, pain/discomfort, and anxiety/depression. The dimensions are rated by the responder as $1=$ no problem, $2=$ some problems, or $3=$ extreme problems. This rating is accompanied by an EQ5D-VAS value between 0 and 100, rating the actual Quality of Life-situation, where 0 is "worst imaginable health state" and 100 is "best imaginable health state" [25].

In addition, a questionnaire that included questions about the subjective pre-operative symptoms such as indication/s for surgery, as well as post-operative experiences was used. The subjective level of symptoms prior to and after surgery for each of the following PPM symptoms was documented: pain, spasticity, motor function, sensory function, hyperhidrosis, and bladder function. The patients were also asked to address the dominating symptoms causing them to seek neurosurgical consultation and consent to neurosurgical treatment. Furthermore, patients were asked if they were satisfied with the result after surgery answering "yes" or "no", thus reflecting their own experience. Finally, patients were also given the possibility to comment, in free text, on their experience from surgery. Patients who had more than one surgery were asked about their satisfaction from surgical treatment after their initial operation.

\section{Statistical analysis}

Normality of data were evaluated with the Kolmogorov-Smirnov test. Normally distributed data are presented as mean \pm standard deviations (SD) and nonnormally distributed data as medians and range, as indicated. Continuous variables were evaluated for statistical significance using the Student's $t$-test or Mann-Whitney U. 
Table 2 Demographic data for initial post-traumatic myelopathy surgery in the included patient cohort

\begin{tabular}{llll}
\hline Characteristics & Respondents $(n=38)$ & Non-respondents $(n=8)$ & $\begin{array}{l}\text { Lost to follow-up } \\
(n=6)\end{array}$ \\
\hline Age at surgery (years) & $43.2 \pm 12.7[22-71]$ & $37.5 \pm 18.0[21-75]$ & $50.5 \pm 17.9[21-66]$ \\
$\begin{array}{l}\text { Time from injury to surgery } \\
\text { (years) }\end{array}$ & $13.3 \pm 9.6[1-32]$ & $6.5 \pm 7.1[1-20]$ & $25.3 \pm 19.1[1-48]$ \\
LOS in hospital (days) & $12.2 \pm 3.6[5-20]$ & $12.1 \pm 3.6[9-19]$ & $13.7 \pm 8.8[8-31]$ \\
\hline
\end{tabular}

Note: Respondents to questionnaires, non-respondents to questionnaires and those lost to follow-up are presented separately

Numbers are presented as mean $+\mathrm{SD}$ and range. LOS length of stay

Categorical variables were evaluated for statistical significance using Fisher's exact test. Analyses were performed using IBM SPSS Statistics for Windows, Version 24.0. Armonk, NY, USA. The significance level was defined as $p$-value below 0.05 .

\section{Results}

\section{Patients}

On initial screening, 64 adult patients were identified. Twelve patients with a non-traumatic etiology were excluded (Fig. 1). Of the remaining 52 patients, their mean age was $43.3 \pm 14.4$ years at time of initial PPM surgery. At follow-up, five patients were deceased with a median survival of 63 months (range 1-125) after surgery. One foreign patient was lost to follow-up, leaving 46 patients (38 male and 8 female) for further analysis. Their demographic data are presented in Table 2. In total, 38 of the 46 patients $(83 \%)$ filled out the EQ-5D instrument, of whom $37(80 \%)$ also filled out the questionnaire. For the respondents of the questionnaires, the median time from SCI to operative treatment was 10.5 years (range 1-32) and the median time from SCI to questionnaire response was 22 years (range 2-48). The median time from initial PPM surgery to questionnaire response was 9 years (range 1-24). Ten patients did not receive any surgical treatment at the time of initial SCI.

\section{Pre-operative symptoms and surgical indications}

According to the medical charts, the dominating preoperative symptoms were pain and deterioration of motor function (Table 1). The primary indication for surgical treatment in patients with PPM was the clinical findings and symptoms and radiological findings of cord tethering and/or syrinx formation were not a prerequisite to proceed to surgery. From the questionnaire, pain and decreased motor function were reported as the most common complaints by the patients themselves. However, hyperhidrosis and bladder dysfunction as dominating complaints leading to surgery were more frequently reported by the patients when compared to the information obtained from the medical charts (Fig. 3a).

\section{Surgical procedure and complications}

The 52 patients had 63 surgical interventions in total. Of these, 37 consisted of untethering of the cord with scar removal, 25 of untethering surgery plus syringosubarachnoid shunt placement for cyst drainage, and in 1 reoperation only cyst drainage by syringo-subarachnoid shunt placement was used. Of the 52 patients, 46 had one surgery, 3 had two, 2 had three and 1 had five surgeries. Post-operative complications were uncommon. One patient developed an extradural fluid accumulation at the surgical site which was conservatively managed, and one was reoperated for CSF leakage at 16 days post-surgery. In addition, one patient developed meningitis which was successfully treated with antibiotics. Finally, one patient in whom a postoperative lumbar drainage was used developed disorientation, dysphasia, and disturbed vision the day after surgery. MRI and CT imaging showed a left temporal intracerebral hemorrhage and some subarachnoidal blood over the right hemisphere. The hemorrhage was conservatively managed, and the patient recovered without sequalae. Two patients dependent on mechanical ventilation prior to surgery, performed due to cranially expanding cysts and cord tethering, died of unrelated causes at 42 and 44 days after surgery, respectively. Cause of death was sepsis and multiorgan failure in the first patient and pneumonia in the other.

\section{Radiological outcome}

A subset of pre-operative $(n=39)$ and post-operative $(n=$ 27) MRI examinations could be located for analysis. No post-operative CT-myelography was performed in any patient. In total, 17 out of 52 patients had untethering surgery 
Fig. 3 Comparison of information from medical charts and questionnaires. a Frequency of reasons for surgery from the medical charts and patients' view from the questionnaire. Note that there is more than one indication for surgery. b Outcome results as described in medicals charts, with patients divided in satisfied vs. dissatisfied with surgery according to their answers to the questionnaire. Note that two patients in the dissatisfied group are not included in the figure as there was no follow-up information
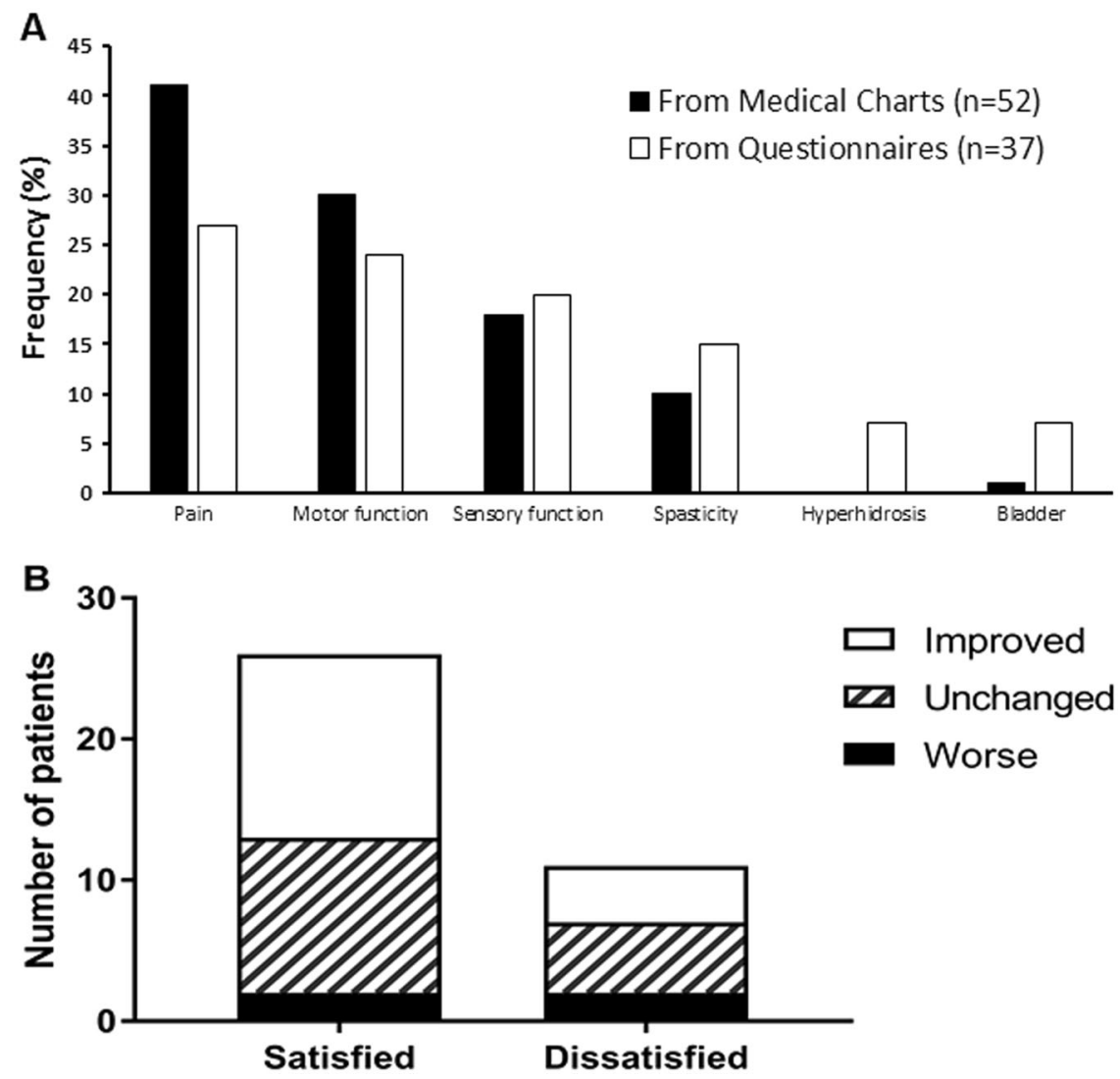

in combination with placement of a syringosubarachnoid shunt (Table 3). The analysis of available MRIs, surgical outcome from the medical charts, and outcome from the questionnaires for this subgroup of patients are presented in Table 3 . In those patients where a pre-operative and post-operative MRI could be compared, 7 out of 9 had either improved or unchanged syrinx size post-operatively. Both patients with worse radiological status on postoperative MRI were dissatisfied with the surgical outcome (Table 3).

In 27 patients, pre-operative and post-operative MRI could be compared (Table 4). Of these patients, 14 had improved radiological status showing decreased tethering and/or syrinx. In 11 patients the radiological appearance was unchanged and in only 3 patients was the status clearly worsened (Table 4).

\section{Outcome}

\section{Assessed from medical charts}

When evaluating the surgeon's follow-up from the medical charts of the 52 surgically treated patients, $87 \%$ had either improved $(n=24)$ or were unchanged $(n=21)$ postoperatively. Five patients $(10 \%)$ reported deterioration of symptoms post-operatively, four in motor function and one in sensory function. Two patients (4\%) were lost to followup (Table 2).

\section{Assessed by questionnaires - patient-reported outcome}

From the questionnaires, 24 patients $(65 \%)$ were satisfied with the surgical results, while 13 patients (35\%) were disappointed (Fig. 3b). Three patients were dissatisfied with the post-operative care and two with the follow-up care. Two patients reported pain worsening and one was disappointed since the pain remained unchanged post-operatively. Two patients reported some degree of deterioration of pre-operative neurological function. Two patients reported progressive neurological deterioration despite surgery, and finally one patient was disappointed since surgery did not provide relief of his pre-existing neurological disability. The results from the EQ-5D instrument and its five dimensions, comparing patients who reported satisfaction vs. dissatisfaction with the surgical treatment, showed that 37 of 38 respondents suffered from pain and/or discomfort. Almost $50 \%$ of the responders satisfied with the surgical treatment reported "no problem" in the EQ-5D dimension anxiety/depression, compared with approximately $20 \%$ in the dissatisfied group $(p>0.05$, data not shown). 
Table 3 Radiological findings in patients $(n=17)$ treated with untethering and syringosubarachnoidal shunt placement

\begin{tabular}{|c|c|c|c|c|c|}
\hline Gender & $\begin{array}{l}\text { Age (years) at } \\
\text { surgery }\end{array}$ & $\begin{array}{l}\text { Rostral level of syrinx } \\
\text { on pre-op MRI }\end{array}$ & $\begin{array}{l}\text { Radiological outcome } \\
\text { compared to pre-op }\end{array}$ & $\begin{array}{l}\text { Outcome from medical } \\
\text { records }\end{array}$ & $\begin{array}{l}\text { Outcome from } \\
\text { questionnaire }(\mathrm{Q})\end{array}$ \\
\hline M & 64 & C3-4 & $\begin{array}{l}\text { Improved, marked reduction of } \\
\text { syrinx size }\end{array}$ & Improved & Dissatisfied \\
\hline M & 65 & Th1 & $\begin{array}{l}\text { Improved, marked reduction of } \\
\text { syrinx size }\end{array}$ & Improved & Satisfied \\
\hline M & 45 & $\mathrm{C} 0$ & $\begin{array}{l}\text { Improved, marked reduction of } \\
\text { syrinx size }\end{array}$ & Unchanged & Satisfied \\
\hline M & 44 & $\mathrm{C} 1$ & $\begin{array}{l}\text { Improved, marked reduction of } \\
\text { syrinx size }\end{array}$ & Unchanged & Satisfied \\
\hline M & 23 & $\mathrm{C} 0$ & $\begin{array}{l}\text { Improved, marked reduction of } \\
\text { syrinx size }\end{array}$ & Worse & Did not answer Q \\
\hline M & 25 & $\mathrm{C} 4$ & $\begin{array}{l}\text { Improved, minor reduction of } \\
\text { syrinx size }\end{array}$ & Unchanged & Satisfied \\
\hline $\mathrm{F}$ & 31 & Th4 & Unchanged & Improved & Satisfied \\
\hline $\mathrm{F}$ & 71 & $\mathrm{~T} 2-12$ & Worse-increased syrinx & Worse & Dissatisfied \\
\hline M & 46 & $\mathrm{C} 2$ & Worse-increased syrinx & Information not available & Dissatisfied \\
\hline $\mathrm{F}$ & 27 & $\mathrm{C} 5$ & No post-op MRI & Improved & Dissatisfied \\
\hline M & 36 & Th6 & No post-op MRI & Improved & Satisfied \\
\hline M & 59 & Th12 & No post-op MRI & Improved & Did not answer Q \\
\hline $\mathrm{F}$ & 48 & Th6 & No post-op MRI & Improved & Did not answer Q \\
\hline M & 38 & $\mathrm{~L} 1$ & No post-op MRI & Improved & Did not answer Q \\
\hline M & 66 & $\mathrm{C} 0$ & No post-op MRI & Unchanged & Did not answer Q \\
\hline M & 24 & $\mathrm{C} 0$ & No post-op MRI & Unchanged & Did not answer Q \\
\hline $\mathrm{F}$ & 62 & Th4 & No post-op MRI & Worse & Did not answer Q \\
\hline
\end{tabular}

Note: In eight of these patients, no post-operative MRI was obtained. In those patients where a post-operative MRI was available $(n=9)$, a majority had either improved $(n=6)$ or unchanged $(n=1)$ syrinx size. Note that both patients with worsened syrinx extension post-operatively were dissatisfied with the surgical treatment. $\mathrm{F}$ female, $\mathrm{M}$ male

The mean level of perceived health status, as measured by EQ-5D-VAS, was significantly higher in the group of patients who were satisfied with surgery $(23 / 36)$, than those dissatisfied (13/36) (mean $=60.1 ; 95 \%$ CI: 53.8-66.4 vs. mean $=44.8 ; 95 \%$ CI: $32.8-66.7$, respectively). There was no difference in mean EQ-5D levels between the groups with complete and incomplete SCI, between men and women, or between patients with cervical vs. thoracic/ thoracolumbar SCI.

Patients with cervical SCI were more satisfied with the surgical outcome than patients with injuries at thoracic/ thoracolumbar levels $(13 / 15$ vs. $11 / 22 ; p<0.05)$.

\section{Discussion}

The present study was conducted with the aim to evaluate the long-term outcome, quality of life, and satisfaction following surgery in patients with traumatic SCI and PPM. Our main findings were: (a) the most common surgical indications were pain and deterioration of motor function, (b) untethering with or without cyst drainage was associated with low number of complications and was well tolerated by the patients, leading to a high degree of patient satisfaction, (c) most patients remained unchanged or improved post-surgery, and (d) patients with injury in cervical spinal cord were more satisfied from surgery than those with more caudal SCIs.

The primary aim of neurosurgical treatment of PPM is to prevent further neurological deterioration and a good surgical outcome is commonly described as improved or unchanged neurological status after surgery $[4,12,16,26]$. Subjectively perceived outcome was improved in a high proportion of patients. In theory, patients with incomplete motor and/or sensory SCI may experience some improvement following untethering surgery $[4,8,10,11]$. However, pain was a common indication for surgery in our series and the reported improvement was due to less pain observed post-operatively. This is supported by previous reports, suggesting improved pain control following untethering surgery $[4,8,10]$. Pain is an exceedingly common problem encountered in chronic SCI patients. Typical features of the pain associated with PPM are a delayed onset and neurogenic characteristics, such as paresthesia and burning pain. Although the mechanisms for post-SCI pain have not been established, there are several plausible mechanisms contributing to the onset and/or worsening of neurogenic pain. 
Table 4 Pre-operative and post-operative MRI of the 27 patients in whom both images could be located and compared

\begin{tabular}{|c|c|c|c|c|c|}
\hline Gender & $\begin{array}{l}\text { Age (years) } \\
\text { at surgery }\end{array}$ & $\begin{array}{l}\text { Time between surgery } \\
\text { and post-op MRI } \\
\text { (months) }\end{array}$ & $\begin{array}{l}\text { Level of } \\
\text { injury }\end{array}$ & $\begin{array}{l}\text { Presence of pre- } \\
\text { op syrinx }\end{array}$ & Radiological outcome \\
\hline $\mathrm{F}$ & 48 & 6 & $\mathrm{C} 5$ & No & Tethering improved \\
\hline M & 52 & 10 & $\mathrm{C} 4$ & No & Tethering improved \\
\hline M & 45 & 8 & Th5-6 & No & Tethering improved \\
\hline M & 27 & 5 & Th11-12 & No & Tethering improved \\
\hline M & 33 & 2 & Th5-6 & No & Tethering improved \\
\hline M & 63 & 1 & $\mathrm{C} 3$ & No & Tethering improved \\
\hline M & 42 & 8 & C6 & No & Tethering improved \\
\hline M & 66 & 9 & $\mathrm{~L} 1$ & No & Unchanged \\
\hline M & 22 & 16 & C4-6 & No & Unchanged \\
\hline M & 32 & 33 & Th7-8 & No & Unchanged \\
\hline M & 41 & 3 & Th6-7 & No & Unchanged \\
\hline $\mathrm{F}$ & 48 & 16 & $\mathrm{C} 4$ & No & Unchanged \\
\hline M & 50 & 6 & $\mathrm{C} 7$ & No & Unchanged \\
\hline M & 49 & 22 & C6 & No & Unchanged \\
\hline M & 30 & 1 & Th12 & No & Unchanged \\
\hline M & 59 & 2 & C6 & No & Unchanged \\
\hline M & 50 & 3 & Th12 & No & Unchanged \\
\hline $\mathrm{F}$ & 31 & 3 & Th6 & Yes & Unchanged \\
\hline M & 64 & 5 & L2 & Yes & $\begin{array}{l}\text { Improved, marked } \\
\text { reduction of syrinx size }\end{array}$ \\
\hline $\mathrm{M}$ & 55 & 1 & T3-4 & Yes & $\begin{array}{l}\text { Improved, marked } \\
\text { reduction of syrinx size }\end{array}$ \\
\hline M & 65 & 12 & Th9-11 & Yes & $\begin{array}{l}\text { Improved, marked } \\
\text { reduction of syrinx size }\end{array}$ \\
\hline M & 44 & 1 & Th8-9 & Yes & $\begin{array}{l}\text { Improved, marked } \\
\text { reduction of syrinx size }\end{array}$ \\
\hline M & 23 & 6 & C6-7 & Yes & $\begin{array}{l}\text { Improved, marked } \\
\text { reduction of syrinx size }\end{array}$ \\
\hline M & 25 & 4 & $\mathrm{C} 5$ & Yes & $\begin{array}{l}\text { Improved, rostral syrinx } \\
\text { reduced }\end{array}$ \\
\hline $\mathrm{F}$ & 71 & 5 & Th6-7 & Yes & $\begin{array}{l}\text { Worse, syrinx expansion } \\
\text { rostrally }\end{array}$ \\
\hline $\mathrm{M}$ & 46 & 6 & Th2 & Yes & $\begin{array}{l}\text { Worse, syrinx expansion } \\
\text { rostrally }\end{array}$ \\
\hline M & 36 & 2 & Th12 & No & $\begin{array}{l}\text { Worse, syrinx expansion } \\
\text { rostrally }\end{array}$ \\
\hline
\end{tabular}

Note: The post-operative MRI was obtained at a median of 7 months (range 1-33 months) post-surgery. In the majority of patients did the postoperative MRI show improved spinal cord tethering and/or syrinx size

Potentially, tethering and/or syrinx formation lead to tissueshearing forces particularly evident during movement, leading to mechanical distortion and local ischemia. SCI may also be accompanied by neuroinflammation, including the activation of microglia and astrocytes that leads to increased production of cytokines commonly attributed with exacerbation of pain. In addition, aberrant plasticity is another plausible mechanism for pain which, however, is unlikely to be influenced by PPM surgery [26-28]. In the current study, most patients $(=63.5 \%)$ had a motor complete SCI
(AIS A + B) which was in agreement with some previous reports [7, 21], although not with others [16]. Therefore, interpretation of functional outcome and clinical improvement should be done with caution. Similarly to previous reports, the time frame between the initial injury, the presentation of PPM, and syringomyelia and surgery in our group of patients was highly variable [4, 6, 14, 16, 21, 29].

The use of cyst drainage and shunting remain controversial. In some previous reports, arachnolysis (removal of the glial scar) without shunting has been 
advised [11, 14, 29, 30]. When cyst shunting was compared to arachnolysis in 34 patients with PPM, cyst drainage was associated with more frequent recurrences and reoperations. Patients treated with arachnolysis also had better clinical results [14]. Further, patients with PPM treated solely with arachnolysis demonstrated an overall positive clinical course with long symptom-free periods [31, 32]. In a series of 61 patients with PPM, cyst shunting was performed only as a second choice, and here arachnolysis, untethering, and duraplasty as primary surgical technique resulted in cyst reduction in $60 \%$ and pain improvement in $47 \%$ of chronic SCI patients [16]. It has been suggested that patients with descending progression of symptoms will likely benefit more from an untethering operation, whereas individuals with ascending symptoms may more frequently require an operation targeted to restore CSF flow $[6,16]$. In our series, untethering surgery was the primary surgical treatment, and only in those patients where the spinal cord syrinx persisted to $>50 \%$ of its initial size after untethering, as evaluated by peroperative ultrasound assessment, a syringosubarachnoid shunt was inserted $[6,12]$.

In a surgical series of 362 patients, a single surgery resulted in arrested progression of motor and sensory symptoms in $86 \%$ of patients without significant change in sensory or motor function. In the same patient cohort, almost half of patients reported some functional improvement, although in this study the percentage of patients with incomplete SCI was not reported [4]. In a study of 45 patients operated for PPM, more than half showed better motor function and improvement in spasticity following surgery. In this particular series, improvement was less in pain and sensory disturbances [6].

Reoperations and complications are not infrequent following surgical untethering and/or cyst drainage for PPM due to cyst recurrence and retethering. In a report of 27 patients, 13 required two or more surgeries and $10 / 16$ of those who underwent cyst drainage needed revision surgery [32]. In a larger series of 362 patients who underwent 420 surgeries, 16 had post-operative CSF leakage (4\%) [4]. In our present study, clinically significant complications were rare. Furthermore, the frequency of reoperations in our patient cohort was similar to earlier reports [4].

Overall, our results show that patient satisfaction following surgery was high, particularly for patients with cervical SCI which may be due to improved pain situation from PPM surgery. It is also plausible that in cervical injuries, even a minor improvement of neurological function caused by PPM surgery could have a significant impact on everyday life and function. Furthermore, patients who were satisfied with the surgical outcome reported a statistically significant higher level of current health status EQ5D-VAS compared to those that were dissatisfied.
Interestingly, in the group of dissatisfied individuals, a higher percentage reported "no problem" with self-care which indicates lower and incomplete injuries.

The present study has some limitations. Baseline data before and after surgery were collected retrospectively and retrieved from the available medical charts. The primary indication for surgical treatment in patients with PPM was the clinical findings and symptoms. Radiological findings of cord tethering and/or syrinx formation were not a prerequisite for surgery, since clinically relevant tethering may not be evident on MRI. When available, post-operative imaging showed improved or unchanged status in the majority of patients. Although the patient number is insufficient to make firm conclusions, no apparent correlation between radiological and clinical outcome could be established. However, an important finding was that both patients treated by syringosubarachnoid shunt who showed worsened syrinx size and extension post-operatively were dissatisfied with the surgical outcome. The post-operative radiological evaluation was incomplete in the present study, since no systematic radiological follow-up was performed. Furthermore, in view of the retrospective nature of our study, old MRI investigations were commonly not available.

The overall time from surgery to the final assessment of quality of life by the patient was long which potentially result in a recall bias. As a consequence, a subset of patients was either dead or lost to follow-up. However, good correlation between the information from the medical charts and the patients' responses was found. Moreover, when the group of patients who responded to the questionnaire was compared to the non-respondent group in age, gender, cause of injury, level of injury, and AIS score, they were found to be comparable. We therefore assume that the group of respondents is representative. Strengths of the present report are that it represents a single-center study, all surgeries were carried out by the same surgeon $(\mathrm{AH})$ using a standardized surgical technique and the results were favorable from the clinical perspective and patient satisfaction.

\section{Conclusions}

The majority of patients with PPM were satisfied with the surgical treatment. The favorable outcome and low complication rate suggest that SCI patients suffering from progressive neurological deterioration from PPM should be offered surgical treatment. However, all persistent patient complaints should be taken seriously, emphasizing the need for detailed pre-operative information regarding what to expect from surgery as well as the post-operative care, rehabilitation and follow-up. 
Although the most important outcome measure following PPM surgery will remain the clinical symptoms, systematic pre-operative and post-operative MR imaging could help refining surgical treatment strategies as well as evaluating the role of imaging findings in PPM symptoms. A remaining concern with PPM surgery, observed in our present series as well as in others, is the rate of re-tethering. Since the cause of ongoing scarring has not been defined, future studies need to evaluate whether altered surgical techniques, pharmacological approaches, or post-operative care strategies can be used to attenuate the risk of re-tethering.

Acknowledgements This study received funds from Uppsala University Hospital (to NM and UH) and the Swedish Research Council and from Personskadeförbundet RTP (to NM).

\section{Compliance with ethical standards}

Conflict of interest The authors declare that they have no conflict of interest.

\section{References}

1. Dell'Anno MT, Strittmatter SM. Rewiring the spinal cord: direct and indirect strategies. Neurosci Lett. 2017;652:25-34.

2. Nandoe Tewarie RD, Hurtado A, Bartels RH, Grotenhuis JA, Oudega M. A clinical perspective of spinal cord injury. NeuroRehabilitation. 2010;27:129-39.

3. Steeves JD, Kramer JK, Fawcett JW, Cragg J, Lammertse DP, Blight AR, et al. Extent of spontaneous motor recovery after traumatic cervical sensorimotor complete spinal cord injury. Spinal Cord. 2011;49:257-65.

4. Falci SP, Indeck C, Lammertse DP. Posttraumatic spinal cord tethering and syringomyelia: surgical treatment and long-term outcome. J Neurosurg Spine. 2009;11:445-60.

5. Wyndaele M, Wyndaele JJ. Incidence, prevalence and epidemiology of spinal cord injury: what learns a worldwide literature survey? Spinal Cord. 2006;44:523-9.

6. Lee TT, Alameda GJ, Camilo E, Green BA. Surgical treatment of post-traumatic myelopathy associated with syringomyelia. Spine. 2001;26:S119-27.

7. Schurch B, Wichmann W, Rossier AB. Post-traumatic syringomyelia (cystic myelopathy): a prospective study of 449 patients with spinal cord injury. J Neurol Neurosurg Psychiatry. 1996;60:61-7.

8. Edgar R, Quail P. Progressive post-traumatic cystic and non-cystic myelopathy. Br J Neurosurg. 1994;8:7-22.

9. Biyani A, el Masry WS. Post-traumatic syringomyelia: a review of the literature. Paraplegia. 1994;32:723-31.

10. el Masry WS, Biyani A. Incidence, management, and outcome of post-traumatic syringomyelia. In memory of Mr Bernard Williams. J Neurol Neurosurg Psychiatry. 1996;60:141-6.

11. Lee TT, Alameda GJ, Gromelski EB, Green BA. Outcome after surgical treatment of progressive posttraumatic cystic myelopathy. J Neurosurg. 2000;92:149-54.
12. Holtz A, Levi R. Spinal cord injury. Oxford University Press; Oxford, England; 2010.

13. Adelstein LJ. The surgical treatment of syringomyelia. Am J Surg. 1938;XL:384-95.

14. Aghakhani N, Baussart B, David P, Lacroix C, Benoudiba F, Tadie M, et al. Surgical treatment of posttraumatic syringomyelia. Neurosurgery. 2010;66:1120-7.

15. Austin JW, Afshar M, Fehlings MG. The relationship between localized subarachnoid inflammation and parenchymal pathophysiology after spinal cord injury. $\mathrm{J}$ Neurotrauma. 2012;29:1838-49.

16. Klekamp J. Treatment of posttraumatic syringomyelia. J Neurosurg Spine. 2012;17:199-211.

17. Rossier AB, Foo D, Shillito J, Dyro FM. Posttraumatic cervical syringomyelia. Incidence, clinical presentation, electrophysiological studies, syrinx protein and results of conservative and operative treatment. Brain. 1985;108:439-61.

18. Greitz D. Unraveling the riddle of syringomyelia. Neurosurg Rev. 2006;29:251-63.

19. Williams B. Pathogenesis of post-traumatic syringomyelia. Br J Neurosurg. 1992;6:517-20.

20. Bonfield CM, Levi AD, Arnold PM, Okonkwo DO. Surgical management of post-traumatic syringomyelia. Spine. 2010;35: S245-58.

21. Krebs J, Koch HG, Hartmann K, Frotzler A. The characteristics of posttraumatic syringomyelia. Spinal Cord. 2016;54:463-6.

22. Ewelt C, Stalder S, Steiger HJ, Hildebrandt G, Heilbronner R. Impact of cordectomy as a treatment option for posttraumatic and non-posttraumatic syringomyelia with tethered cord syndrome and myelopathy. J Neurosurg Spine. 2010;13:193-9.

23. Hayashi T, Ueta T, Kubo M, Maeda T, Shiba K. Subarachnoidsubarachnoid bypass: a new surgical technique for posttraumatic syringomyelia. J Neurosurg Spine. 2013;18:382-7.

24. Sgouros S, Williams B. A critical appraisal of drainage in syringomyelia. J Neurosurg. 1995;82:1-10.

25. EuroQolGroup. EuroQol-a new facility for the measurement of health-related quality of life. Health Policy. 1990;16:199-208.

26. Lee TT, Arias JM, Andrus HL, Quencer RM, Falcone SF, Green BA. Progressive posttraumatic myelomalacic myelopathy: treatment with untethering and expansive duraplasty. J Neurosurg. 1997;86:624-8.

27. Grace PM, Hutchinson MR, Maier SF, Watkins LR. Pathological pain and the neuroimmune interface. Nat Rev Immunol. 2014; $14: 217-31$

28. Grau JW, Huang YJ, Turtle JD, Strain MM, Miranda RC, Garraway SM, et al. When pain hurts: nociceptive stimulation induces a state of maladaptive plasticity and impairs recovery after spinal cord injury. J Neurotrauma. 2017;34:1873-90.

29. Vernon JD, Silver JR, Symon L. Post-traumatic syringomyelia: the results of surgery. Paraplegia. 1983;21:37-46.

30. Klekamp J, Batzdorf U, Samii M, Bothe HW. Treatment of syringomyelia associated with arachnoid scarring caused by arachnoiditis or trauma. J Neurosurg. 1997;86:233-40.

31. Ghobrial GM, Dalyai RT, Maltenfort MG, Prasad SK, Harrop JS, Sharan AD. Arachnolysis or cerebrospinal fluid diversion for adult-onset syringomyelia? A systematic review of the literature. World Neurosurg. 2015;83:829-35.

32. Karam Y, Hitchon PW, Mhanna NE, He W, Noeller J. Posttraumatic syringomyelia: outcome predictors. Clin Neurol Neurosurg. 2014;124:44-50. 